\title{
ERRATUM
}

Glynis Jones • Soultana M. Valamoti

\section{Lallemantia, an imported or introduced oil plant in Bronze Age northern Greece}

Published online: 28 September 2006

(C) Springer-Verlag 2005

\section{Veget Hist Archaeobot (2005) 14:571-577}

Unfortunately there were some errors in Source of the seeds section at end of the fourth paragraph. The paragraph should read:

Other species, such as Triticum spelta L. (spelt wheat), Panicum miliaceum L. (common millet), Vicia faba L. (Celtic bean) and Papaver somniferum L. (opium poppy), also make their first appearance in Greece at various times during the Bronze Age (Kroll 1991; Zohary and Hopf 2000; Valamoti and Jones 2003; Valamoti 2004; Valamoti in press). These finds of Lallemantia therefore add to the evidence for the introduction of new crops during the course of the Bronze Age, perhaps related to increased external contact during this period with regions to the east or possibly north of Greece. It is not possible to say, at this stage, whether Lallemantia arrived in Greece through Anatolia or via a route to the north of the Black Sea.

The online version of the original article can be found at http://dx.doi.org/10.1007/s00334-005-0004-z

G. Jones $(\bowtie)$

Department of Archaeology,

Northgate House, West Street,

Sheffield, S1 4ET, United Kingdom

e-mail: g.jones@sheffield.ac.uk

S. Valamoti

Department of Archaeology,

Aristotle University of Thessaloniki,

54006 Thessaloniki, Greece

e-mail:sval@hist.auth.gr 